\title{
Connecting Lunar Meteorites to Source Terranes on the Moon
}

\author{
B. L. Jolliff ${ }^{1}$, P. K. Carpenter ${ }^{1}$, R. L. Korotev ${ }^{1}$, S. N. North-Valencia ${ }^{1}$, A. Wittmann ${ }^{1}$, and R. A. Zeigler ${ }^{2}$ \\ ${ }^{1}$ Washington University in St. Louis, Department of Earth and Planetary Sciences and the McDonnell Center for \\ the Space Sciences, St. Louis, MO 63130; ${ }^{2}$ NASA Johnson Space Center, Houston, TX, USA.
}

The number of named stones found on Earth that have proven to be meteorites from the Moon is $~ 180$ so far. Since the Moon has been mapped globally in composition and mineralogy from orbit, it has become possible to speculate broadly on the region of origin on the basis of distinctive compositional characteristics of some of the lunar meteorites. In particular, Lunar Prospector in 1998 [1,2] mapped Fe and Th at 0.5 degree/pixel and major elements at 5 degree/pixel using gamma ray spectroscopy. Also, various multispectral datasets have been used to derive $\mathrm{FeO}$ and $\mathrm{TiO}_{2}$ concentrations at $100 \mathrm{~m}$ /pixel spatial resolution or better using UV-VIS spectral features [e.g., 3]. Using these data, several lunar meteorite bulk compositions can be related to regions of the Moon that share their distinctive compositional characteristics. We then use EPMA to characterize the petrographic characteristics, including lithic clast components of the meteorites, which typically are breccias. In this way, we can extend knowledge of the Moon's crust to regions beyond the Apollo and Luna sample-return sites, including sites on the lunar farside.

Feldspathic Regolith Breccias. One of the most distinctive general characteristics of many lunar meteorites is that they have highly feldspathic compositions $\left(\mathrm{Al}_{2} \mathrm{O}_{3} \sim 28 \% \mathrm{wt} . \%, \mathrm{FeO}<5 \mathrm{wt} . \%\right.$, Th $\left.<1 \mathrm{ppm}\right)$. These compositions are significant because they are similar to a vast region of the Moon's farside highlands, the Feldspathic Highlands Terrane, which are characterized by low Fe and Th in remotely sensed data [4]. The meteorites provide a perspective on the lithologic makeup of this part of the Moon, specifically, how anorthositic is the surface and what, if any, are the mafic lithic components? These meteorites are mostly regolith breccias dominated by anorthositic lithic clasts and feldspathic glasses, but they do also contain a variety of more mafic clasts. On the basis of textures, we infer these clasts to have formed by large impacts that excavated and mixed rocks from depth within the lunar crust and possibly the upper mantle. One of the key questions is whether the mafic materials are ferroan or magnesian, which remote sensing does not clearly distinguish, and if mafic, whether they might contain mantle-derived components such as olivine (dunite). Many but not all have mainly ferroan mafic components, consistent with a ferroan crustal source that is complementary to the ferroan anorthositic suite and that represents primary magma-ocean-derived feldspathic crust. Meteorites such as ALH 81005 [5] and Shişr 161 [6], however, contain coarse-grained magnesian mafic clasts (Fig. 1a) derived from deeply seated and melted material associated with impact basins. Comparison to LP gamma-ray data [2] supports an origin for magnesian feldspathic meteorites such as these (e.g., Shişr 161) as shown in Fig. 1 b.

Sayh al Uhaymir (SaU) 169. Another distinctive but much less common composition is represented by relatively mafic impact-melt breccia that is rich in incompatible elements known as KREEP. These meteorites can be related to the western nearside Procellarum KREEP Terrane, especially through a combination of Fe and Th contents. Among the most enriched is SaU 169, which has been related to high-Th impact-melt breccia found at the Apollo 12 site [7]. Through detailed EPMA and ion microprobe analysis we have shown that these two rock types are related in age and origin.

Northwest Africa (NWA) 773 Clan. A distinctive meteorite group that contains a suite of lithic clast types appearing to be petrogenetically related, termed the NWA 773 clan, may also have originated in the Procellarum KREEP Terrane. This clan consists of rock types that seem to represent a volcanic (basaltic) component and a related hypabyssal gabbroic suite representing different members formed along a common liquid line of descent $[8,9]$. Although not highly enriched in incompatible elements, this suite does exhibit a modest enrichment similar to that found in an Apollo 14 green volcanic glass group [8], providing a potential tie to this general location on the lunar surface. 
Dhofar 961. We have reported on a meteorite with clast composition that suggests an origin in the unsampled farside South Pole-Aitken (SPA) basin [10,11]. The SPA basin is the largest on the Moon, with a diameter $>2200 \mathrm{~km}$. Geophysics and petrologic modeling suggest that the impact produced a thick sea of impact melt that differentiated to produce a noritic upper layer [12]. Dhofar 961 contains prominent impact-melt clast components that may represent both the shallow differentiated SPA melt and deeper olivine-bearing impact melt (both reworked by more recent impacts) (Fig. 2). A very young, small impact crater in northern SPA near Maksutov Crater could be the source cater for this meteorite (Fig. 3).

\section{References:}

[1] Lawrence et al. (2000) J. Geophys. Res. 105, 20,307-320,331.

[2] Prettyman et al. (2006) J. Geophys. Res. 111, E12007.

[3] Lucey et al. (1998) J. Geophys. Res. 103, 3679-3699.

[4] Korotev et al. (2003) Geochim. Cosmochim. Acta 67, 4895-4923.

[5] Korotev et al. (1983) Geophys. Res. Lett. 10, 829-832.

[6] Wittmann et al. (2014) Am. Mineral. (in review).

[7] Liu et al. (2012) Earth Planet. Sci. Lett. 319-320, 277-286

[8] Jolliff et al. (2003) Geochim. Cosmochim. Acta 24, 4857-4879

[9] North-Valencia et al. (2014) This Conference.

[10] Jolliff et al. (2009) Lunar Planet. Sci. 40, \#2555.

[11] Zeigler et al. (2013) Lunar Planet. Sci. 44, \#2437.

[12] Vaughan et al. (2014) Planet. Space Sci. 91, 101-106.

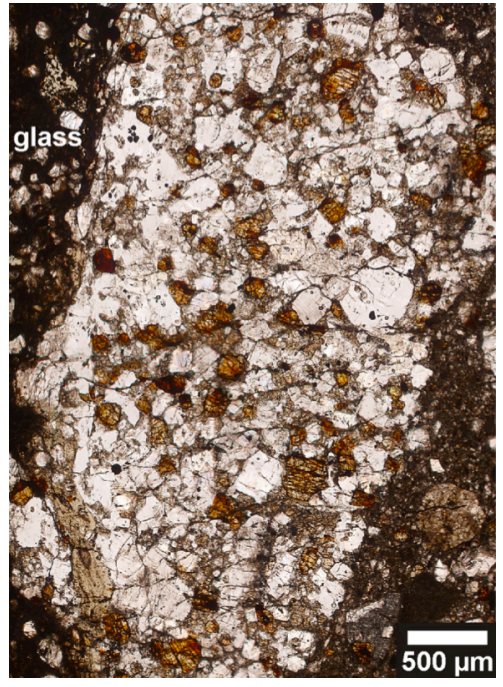

Figure 1. (left) Plane polarized image of magnesian clast with plagioclase (white), olivine (brown), and pyroxene (gray) in Shisr 161. (right) Most likely provenance of Shisr 161 on the Moon (blue squares indicate best matches of Shişr 161 bulk composition with Lunar Prospector 5-degree/pixel data).

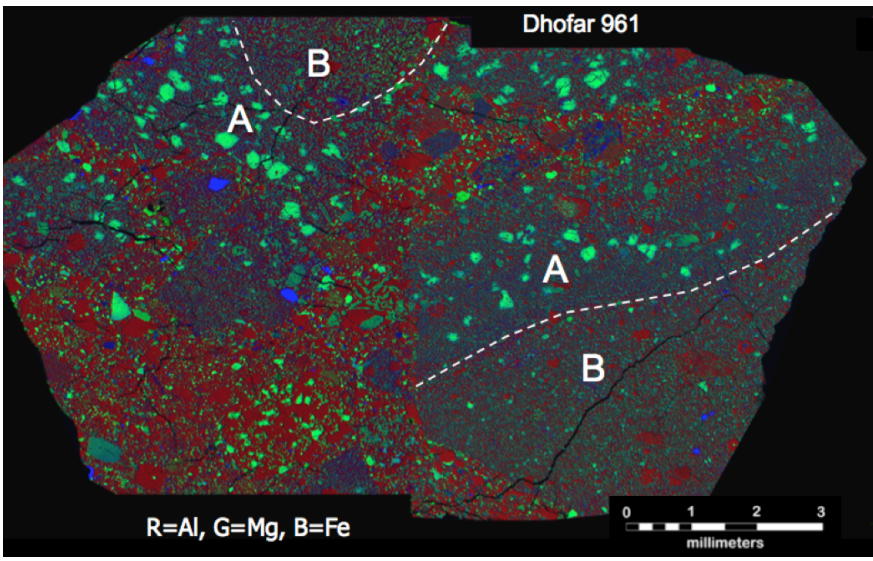

Figure 2. X-ray composite image showing the two distinct impact-melt lithologies; A contains olivine phenocrysts (green).

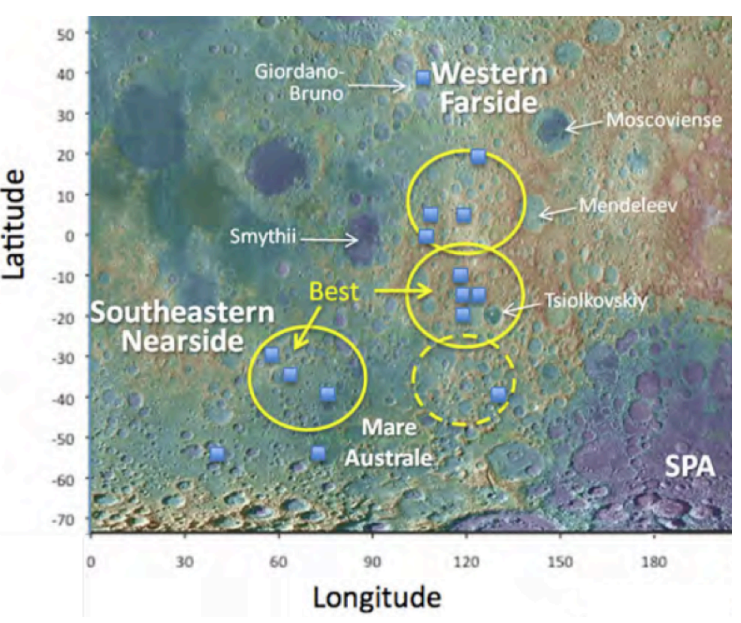

LRO Wide Angle Camera and GLD100 DTM base map

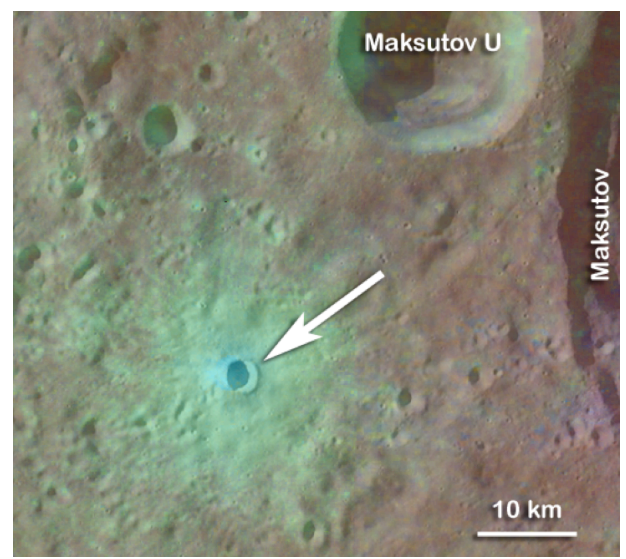

Figure 3. Small, young crater at $41.4^{\circ} \mathrm{S}$ Lat, 171.8 ${ }^{\circ} \mathrm{W}$ Lon; possible source of Dhofar 961. 